\title{
El interés superior del niño en su acogimiento familiar e institucional
}

The best interests of the child in his or her family and institutional foster care

\author{
Johanna Emperatriz Coronel-Piloso \\ uq.docentetp28@uniandes.edu.ec \\ Universidad Regional Autónoma de los Andes, Quevedo \\ Ecuador \\ https://orcid.org/0000-0002-1331-6325 \\ Orlando Iván Ronquillo-Riera \\ uq.orlandoronquillo@uniandes.edu.ec \\ Universidad Regional Autónoma de los Andes, Quevedo \\ Ecuador \\ https://orcid.org/0000-0001-6020-7255 \\ Johnatan Amable Pilataxi-Chucad \\ dq.johnatanapc92@uniandes.edu.ec \\ Universidad Regional Autónoma de los Andes, Quevedp \\ Ecuador \\ https://orcid.org/0000-0002-4211-5039
}

Recepción: 15 de marzo 2021

Revisado: 25 de mayo 2021

Aprobación: 15 de junio 2021

Publicación: 01 de Julio 2021 


\section{Estimado Editor (a):}

El interés superior del niño, tiene la finalidad de proteger a los niños, niñas y adolescente por medio de diferentes acciones legales, garantizando una vida digna al menor, y el respeto de sus derechos en los diferentes marcos de la ley, obteniendo como resultado un desarrollo integral, pues en caso de vulneración de sus derechos se deberán tomar las medidas necesarias para protegerlo, en la actualidad en el Estado ecuatoriano en cada cantón existe la Junta de protección de derechos, la misma que tiene la obligación de velar por los derechos del menor, teniéndolo siempre como prioridad y actuando de manera inmediata. En este sentido para López, Delgado, Carvalho, y Del Valle (2014, p.867), el acogimiento familiar supone una medida más normalizadora, ya que el niño se integra en otro hogar con unas figuras parentales y ambiente de tipo familiar. Diferentes modalidades:

a) La distinción básica entre acogimiento simple, definido como una medida de carácter transitorio que permite a un menor ser acogido en una familia mientras se soluciona la situación que provocó su salida de su núcleo familiar.

b) Acogimiento permanente, para las situaciones en las que no es viable la reunificación del menor dentro con su familia de origen ni es posible la adopción.

c) A estas modalidades se sumaría la del acogimiento provisional, mediante la cual la entidad pública puede llevar a cabo un acogimiento familiar sin el consentimiento de los padres.

Cabe destacar que todo niño, niña puede y tiene el derecho a ser escuchado en diversas instituciones públicas y lograr brindarles la ayuda necesaria que ellos requieran, alcanzando así que sus derechos no sean vulnerados. Por esto es significativo tener en cuenta lo planteado por López Contreras (2015):

El Interés superior de los niños y niñas es el principio fundamental y de aplicación obligatoria en los procesos de Niñez y Adolescencia. Este principio se encuentra establecido de manera fundamental en el artículo 3 de la Convención Sobre los Derechos de los niños y niñas. EL ISNN se puede definir como la potenciación de los derechos a la integridad física y psíquica de cada uno de los niños y niñas, persiguiendo la evolución y desarrollo de su personalidad en un ambiente sano y agradable... (p.55) 
Sin embargo, es importante analizar y garantizar lo relevante de una inserción en hogares adecuados de aquellos niños que se encuentran en centros de acogida o en situación riesgosa en sus hogares, con el fin de precautelar la integridad de aquellos y por ende su correcto desarrollo, esta decisión de acogimiento es de gran valor en la vida del menor ya que claramente afectará a su desarrollo integral de una manera negativa o positiva. Al respecto López Escobar (2015) indica:

El acogimiento se refiere a la atención integral que necesita el niño, niña o adolescente en la entidad, convirtiéndose ésta en su domicilio temporal; conlleva una intervención multidisciplinaria en el medio socio-familiar de cada niño, niña o adolescente, trabajando con su familia de origen con el objeto de prestar el apoyo necesario, hasta lograr la superación de las condiciones que motivaron la separación de su familia, puesto que corresponde privilegiar la reinserción con el/ la/ o los progenitores o su familia ampliada, salvo excepciones ordenadas por la autoridad competente. (p.10)

En este sentido el Estado debe garantizar en conjunto con la familia el bien superior de los niños por sobre todas las cosas ya que lo más importante es brindar un beneficio integral y sano para el buen desarrollo de los niños, como futuros ciudadanos de una Nación. Paulette Murillo, Banchón Cabrera, y Vilela Pincay (2020) presentan:

Los orígenes de la protección integral de la niñez y adolescencia, develan dos doctrinas diametralmente opuestas, una fundamentada en la relación adulto-menor mediada por el tutelaje, donde las niñas, niños y adolescentes no eran considerados sujetos de derecho, se concebían como objeto de patrocinio e intervención; por otro lado, se encuentra la doctrina de protección integral, que los reconoce como sujetos de derechos y que precisa del Estado la modificación de los marcos legales. (p.387)

En siguiente cuadro se muestra las normas que protege y establece lo relacionado a la protección de los menores en el Ecuador: 


\section{Cuadro 1.}

Normativa Legal.

\begin{tabular}{|l|l|}
\hline \multicolumn{1}{|c|}{ Apoyo legal } & \multicolumn{1}{|c|}{ Desarrollo } \\
\hline $\begin{array}{l}\text { Constitución de la República del Ecuador } \\
\text { (2008) }\end{array}$ & $\begin{array}{l}\text { Artículo. 44.- El Estado, la sociedad y la } \\
\text { familia promoverán de forma prioritaria el } \\
\text { desarrollo integral de las niñas, niños y } \\
\text { adolescentes, y asegurarán el ejercicio } \\
\text { pleno de sus derechos; se atenderá al } \\
\text { principio de su interés superior y sus } \\
\text { derechos prevalecerán sobre los de las } \\
\text { demás personas. }\end{array}$ \\
\hline Código de la Niñez y Adolescencia (2003) & $\begin{array}{l}\text { Artículo. 220.- Concepto y finalidad. - El } \\
\text { acogimiento familiar es una medida temporal } \\
\text { de protección dispuesta por la autoridad } \\
\text { judicial, que tiene como finalidad brindar a un } \\
\text { niño, niña o adolescente privado de su } \\
\text { medio familiar, una familia idónea y } \\
\text { adecuada a sus necesidades, } \\
\text { características y condiciones. Durante la } \\
\text { ejecución de esta medida, se buscará } \\
\text { preservar, mejorar o fortalecer los vínculos } \\
\text { familiares, prevenir el abandono y procurar } \\
\text { la inserción del niño, niña o adolescente a su } \\
\text { familia biológica, involucrando a } \\
\text { progenitores y parientes. } \\
\text { Artículo. 232.- Concepto y finalidad. - El } \\
\text { acogimiento institucional es una medida } \\
\text { transitoria de protección dispuesta por la } \\
\text { autoridad judicial, en los casos en que no } \\
\text { sea posible el acogimiento familiar, para } \\
\text { aquellos niños, niñas o adolescentes que se } \\
\text { encuentren privados de su medio familiar. } \\
\text { Esta medida es el último recurso y se } \\
\text { cumplirá únicamente en aquellas entidades } \\
\text { de atención debidamente autorizadas. }\end{array}$ \\
\hline
\end{tabular}

Elaboración: Los autores.

En la actualidad los niños, niñas y adolescentes gozan de sus derechos tal como la Constitución de la República del Ecuador lo consagra, ya que son parte de los grupos de atención prioritaria, por lo tanto, es importante velar por sus derechos y poder garantizarle una vida digna y su pleno desarrollo infantil. Sin embargo, para Fernández Daza (2018) queda mucho por hacer: 
El acogimiento familiar es una de las modalidades que se utilizan para el cuidado alternativo en medio familiar de niños y adolescentes que se encuentran sin la protección de sus padres. Aunque en lberoamérica es notable el interés al respecto, aún queda un largo camino por recorrer. (p.269)

Se debe considerar que las dificultades culturales en la sociedad, el irrespeto de los seres humanos de los derechos de los niños, niñas y adolescentes, son causas de la vulneración de la protección de los menores; por lo tanto, los padres deberán ser los primeros garantes en avalar los derechos de los menores ya que son los responsables de velar por sus derechos, ya sea la protección, la comprensión, la tolerancia, la paz y la educación, además todo debe comenzar en el seno de la familia. Por otro lado, el Estado deberá garantizar sus derechos mediante sus leyes expuestas en cada uno de los códigos vigentes sobre el interés superior del niño en su acogimiento familiar e institucional. Por falta de familiares, los niños son derivados a las diferentes instituciones de casas de acogimientos fuera de su ciudad natal, ocasionando en algunos casos baja autoestima y la disminución del desarrollo integral de crecimiento. Se sugiere que las instituciones públicas o privadas u organizaciones que trabajan para los menores, dicten charlas o campañas para sensibilizar a sus progenitores ya que a través de problemas intrafamiliares conllevan a tomarse estas medidas escogientes y los únicos perjudicados son los menores.

\section{FINANCIAMIENTO}

No monetario.

\section{AGRADECIMIENTO}

A la Universidad Regional Autónoma de los Andes, Ecuador; por motivar el desarrollo de la Investigación. 


\section{REFERENCIAS CONSULTADAS}

Asamblea Nacional Constituyente de la República del Ecuador, (2008). Constitución de la República del Ecuador. Montecristi. Registro Oficial 449 de 20-oct-2008. Recuperado de https://n9.cl/sia

Congreso Nacional. (2003). Código de la niñez y adolescencia. [Childhood and Adolescence Code]. Quito.

Fernández Daza, M. (2018) El acogimiento familiar en Iberoamérica. [Foster care in Latin America]. Saúde e Sociedade. 27(1),268-289. https://doi.org/10.1590/S0104-12902018170647

López Contreras, R. (2015) Interés superior de los niños y niñas: definiciones y contenido. [Best interests of children: definitions and content]. Revista Latinoamericana de Ciencias Sociales, Niñez y Juventud, 13 (1), 51-70. DOI: $\underline{10.11600 / 1692715 \times .1311210213}$

López Escobar, T. (2015) La institucionalidad y el desarraigo familiar de los niños, niñas y adolescentes de las casas de acogida de la ciudad de Ambato. Tesis de maestría. Universidad Técnica de Ambato. Recuperado de: https://n9.cl/kp0ck

López, M., Delgado, P., Carvalho, J. y Del Valle, J. (2014). Características y desarrollo del acogimiento familiar en dos países con fuerte tradición de acogimiento residencial: España y Portugal. [Characteristics and Development of Foster Care in Two Countries with a Strong Tradition of Residential Care: Spain and Portugal]. Universitas Psychologica, 13(3), 865-880. http://dx.doi.org/10.11144/ Javeriana.UPSY13-3.cdaf

Paulette Murillo, K., Banchón Cabrera, J., y Vilela Pincay, W. (2020). El principio de interés superior del niño en el marco jurídico ecuatoriano. [ The principle of the best interests of the child in the Ecuadorian legal framework]. Revista Universidad y Sociedad, 12(2), 385-392. Recuperado de: https://n9.cl/9b9a

\footnotetext{
(C2021 por los autores. Este artículo es de acceso abierto y distribuido según los términos y condiciones de la licencia Creative Commons Atribución-NoComercial-Compartirlgual 4.0 Internacional (CC BY-NC-SA 4.0) (https://creativecommons.org/licenses/by-nc-sa/4.0/).
} 